\title{
Ultrasound-Guided Femoral and Sciatic Nerve Blocks in an Anticoagulated Patient. Case Reports
}

\author{
Leonardo Henrique Cunha Ferraro 1, Maria Angela Tardelli, TSA 2, Américo Masafuni Yamashita, TSA ${ }^{3}$, \\ José Daniel Braz Cardone ${ }^{4}$, Juliana Midori Kishi ${ }^{4}$
}

\begin{abstract}
Summary: Ferraro LHC, Tardelli MA, Yamashita AM, Cardone JDB, Kishi JM - Ultrasound-Guided Femoral and Sciatic Nerve Blocks in an Anticoagulated Patient. Case Reports.

Background and objectives: The use of the ultrasound to guide the puncture in peripheral nerve blocks has become increasingly more frequent. With the lower probability of promoting vascular damage the ultrasound has become an interesting tool in peripheral nerve blocks especially in patients in use of anticoagulants or with coagulopathies. The objective of this article was to report two cases in which ultrasound-guided sciatic and femoral nerve blocks were performed in anticoagulated patients.
\end{abstract}

Case Reports: In the first case, the patient underwent amputation of the left forefoot due to necrosis and signs of infection, and in the second case, surgical cleaning of the left knee. Patients had changes in coagulation with levels of activity of prothrombin and activated partial thromboplastin time above normal limits. Both patients underwent ultrasound-guided femoral and sciatic nerve blocks, evolving without motor or sensorial changes in the territories of those nerves and without hematoma at the site of puncture.

Conclusions: Anticoagulation imposes some restrictions to classical regional anesthetic techniques. With the development of ultrasound equipment and methods, it is now possible to accurately identify vascular and neural structures. This allows ultrasound-guided puncture to be more precise, both to achieve the area of interest and to minimize the risks of accidental vascular damage. Until now, peripheral block was not recommended in anticoagulated patients or in those with coagulopathies. However, considering that few reports on ultrasound-guided regional blocks in coagulopathies can be found in the literature, the safety of this technique in this condition has yet to be established.

Keywords: ANESTHETIC TECHNIQUES, Regional: femoral nerve block, sciatic nerve block; BLOOD: coagulation; DRUGS: anticoagulants; EQUIPMENT, Ultrasound.

[Rev Bras Anestesiol 2010;60(4): 422-428] @Elsevier Editora Ltda.

\section{INTRODUCTION}

The use of the ultrasound to guide puncture in peripheral nerve blocks has become increasingly more frequent. Some benefits of this technique over neurostimulation have been demonstrated in the literature. Among them, we should mention: lower incidence of failures, less time for execution, lower latency, greater duration of the blockade, and lower risk of accidental vascular puncture ${ }^{1-9}$.

Cases in which the ultrasound-guided infra- ${ }^{19}$ and supraventricular ${ }^{11}$ cervical plexus block was successfully used in anticoagulated patients have been reported.

With the lower probability of promoting vascular lesions, the ultrasound has become an interesting tool to guide peri-

Received from Universidade Federal de São Paulo - Escola Paulista de Medicina (UNIFESP EPM), São Paulo, SP

1. Anesthesiologist of Hospital São Paulo - UNIFESP-EPM; Preceptor of Residents at CETUNIFESP-EPM

2. Anesthesiology, Pain, and Intensive Care Professor - UNIFESP-EPM

3. Anesthesiology, Pain, and Intensive Care Professor - UNIFESP-EPM

4. Anesthesiologist of Hospital São Paulo UNIFESP-EPM

Submitted on March 24, 2010

Approved on April 5, 2010

Correspondence to:

Dr. Leonardo Henrique Cunha Ferraro

Rua Napoleão de Barros, 715 - 4ํAndar

04024-002 - São Paulo, SP

E-mail: leohcferraro@yahoo.com.br pheral blocks, especially in patients using anticoagulants or with coagulopathies. Those patients impose some challenges for the realization of regional anesthesia due to the risk of hemorrhagic complications in case of a vascular lesion especially when they happen in places in which compression of the blood vessel is difficult.

Despite the benefits mentioned, a consensus regarding the indication of ultrasound-guided peripheral nerve blocks in the patient with altered coagulation does not exist.

We present here two case reports in which ultrasound guided femoral and sciatic nerve blocks were performed in anticoagulated patients.

\section{CASE REPORTS}

\section{Case 1}

This is a 65 years old male patient complaining of pain in the left leg and foot, under investigation for pulmonary infection. Evaluation of the left foot by vascular surgery observed the presence of necrosis in the $1^{\text {st }}, 2^{\text {nd }}, 3^{\text {rd }}$, and $4^{\text {th }}$ toes and a wound with signs of infection in the anterior region, and an urgent amputation was indicated. He had a history of hypertension, dyslipedemia, chronic bilateral arterial obstruction, chronic obstructive pulmonary disease, chronic renal failure 
on hemodialysis, smoking (50 packs/year), and alcoholism. $\mathrm{He}$ had a femoro-popliteal graft on the left performed three years ago, and he was on the $15^{\text {th }}$ postoperative day of angioplasty of the left iliac artery. He was taking the following drugs: acetylsalicylic acid, $100 \mathrm{mg}$ day $^{-1}$, clopidogrel $75 \mathrm{mg}$. day $^{-1}$, captopril $75 \mathrm{mg}$ day $^{-1}$, propranolol $80 \mathrm{mg}^{-d_{a y}{ }^{-1} \text {, and }}$ omeprazole $20 \mathrm{mg}$ day $^{-1}$. Preoperative exams: hemoglobin = 7.9 g. $\mathrm{dL}^{-1}$; hematocrit $=22.6 \%$; leukocytes $=13,100 / \mathrm{uL}$; platelets $=263,000 \mathrm{u} / \mathrm{L}$; prothrombin activity $=30 \%$; international normalized ratio $=3.39$; activated thromboplastin time $=$ 172.4 seconds with normalized ratio of 6.63 ; creatinine $=$ $6.30 \mathrm{mg} \cdot \mathrm{dL}^{-1} ; \mathrm{BUN}=71 \mathrm{mg} \cdot \mathrm{dL}^{-1}$; sodium $=135 \mathrm{mmol} . \mathrm{L}^{-1} ; \mathrm{po}-$ tassium $=4.1 \mathrm{mmol} \cdot \mathrm{L}^{-1} ;$ magnesium $=1.5 \mathrm{mg} \cdot \mathrm{dL}^{-1}$, and phosphorus $=4.6 \mathrm{mg}^{-\mathrm{dL}^{-1}}$.

It was decided to perform a regional block (femoral and sciatic) for the surgery. The patient arrived to the operating room with a central venous access in the left internal jugular vein and a nasogastric tube. Monitoring consisted of noninvasive blood pressure, pulse oximetry, and cardioscope. Intravenous midazolam $2 \mathrm{mg}$, and fentanyl $50 \mu \mathrm{g}$ were administered. The wide band transducer 5-10 MHz (Sonosite, Titan) was placed on the left inguinal region to allow visibility of the femoral artery and vein. After identifying the femoral nerve, a $22 \mathrm{G}$ isolated needle 5-cm long (Stimuplex A50®, B. Braun, Germany) was introduced longitudinally to the ultrasound beam (in plane technique) until the site of the nerve. Once positioning was confirmed by imaging and response to neurostimulation, $20 \mathrm{~mL}$ of $0.375 \%$ bupivacaine were injected (Figure 1). After the femoral block the patient was placed in the right lateral decubitus for the sciatic nerve block. The image was obtained by an ultrasound of the left infragluteal region to identify the nerve structure. The needle was introduced and the site of injection was confirmed, similar to the femoral nerve block (Figure 2). Additional $20 \mathrm{~mL}$ of $1.5 \%$ lidocaine were injected (Figure 3). The surgical procedure was performed without intercurrences, lasting 1 hour and 45 minutes.

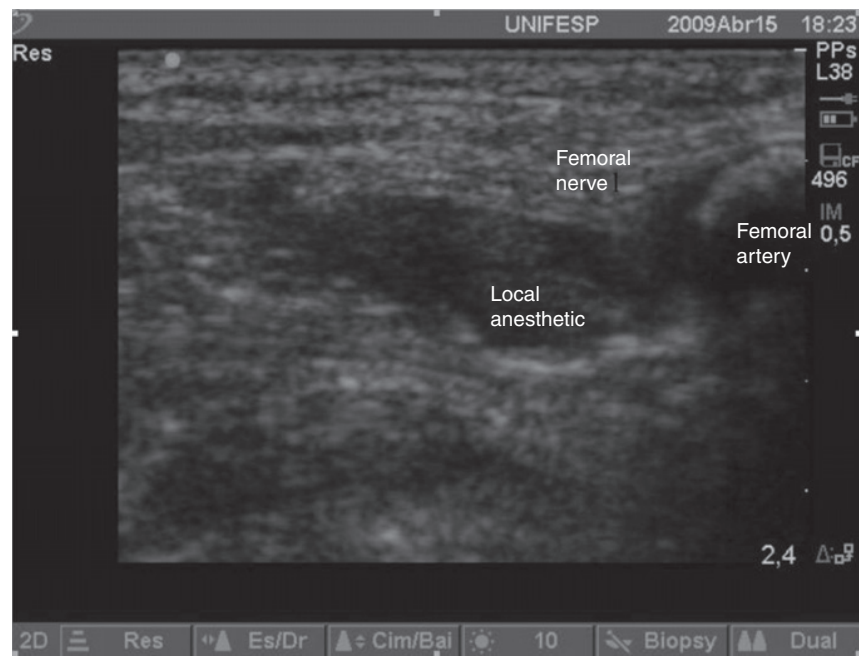

Figure 1 - Transversal View of the Inguinal Region. The femoral nerve, hyperechoic, is located laterally to the femoral artery and it is involved by the local anesthetic. Image obtained with a linear 5-10 MHz transducer (Sonosite, Titan).

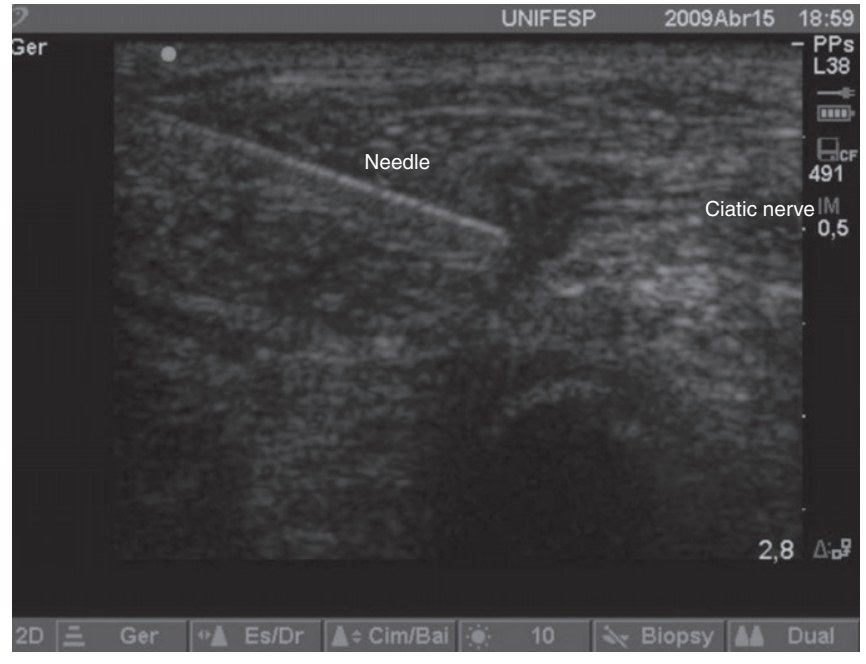

Figure 2 - Transversal View of the Infragluteal Region. Note the sciatic nerve that presents as a hyperechoic and elliptical image.

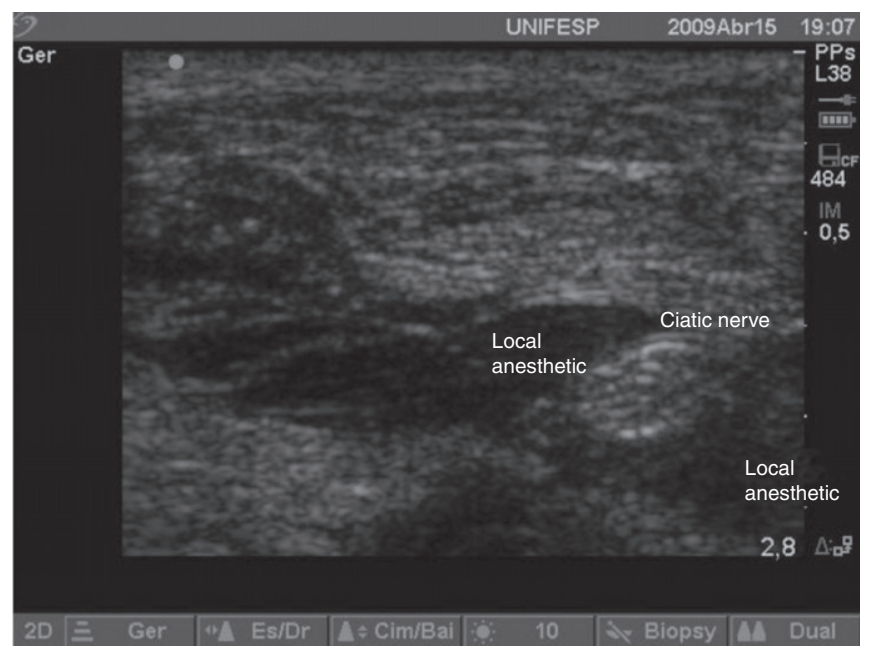

Figure 3 - Transversal View of the Infragluteal Region. The sciatic nerve is involved by the local anesthetic. Image obtained by a 5-10 MHz linear transducer (Sonosite, Titan).

In the postoperative period, the perfusion of the limb was evaluated by Doppler, and the neurological exam was performed to determine the motor response in the territory of the femoral and sciatic nerves, and both were within normal limits. On physical exam, development of hematoma at the site of the puncture was not observed. The patient remained without complaints of pain in the first 10 hours after the blockade.

\section{Case 2}

A 71 years old male patient who arrived at the emergency room complaining of pain in the left knee associated with edema and increased temperature and with difficulty walking for one week. Articular puncture showed a purulent fluid, and antibiotic therapy with oxacillin and ceftriaxone was instituted and urgent surgical debridement was indicated. The patient had a history of hypertension, chronic renal failure on con- 
servative treatment, congestive heart failure, chronic atrial fibrillation, myocardial ischemia two years ago, former smoker (60 packs/year), former alcoholism, chronic arterial obstruction, and left femoro-popliteal graft 5 years ago. He was taking the following medications: acetylsalicylic acid 100 mg.day $^{-1}$, warfarin $5 \mathrm{mg}^{\text {day }}{ }^{-1}$, captopril $150 \mathrm{mg}^{\text {day }}{ }^{-1}$, carvedilol $50 \mathrm{mg}$. day $^{-1}$, furosemide 80 mg.day ${ }^{-1}$, simvastatin 20 mg.day ${ }^{-1}$. Preoperative exams: hemoglobin $=9.4 \mathrm{~g} \cdot \mathrm{dL}^{-1}$; hematocrit $=27.8 \%$; leukocytes: $10,500 \mathrm{u} / \mathrm{L}$; platelets $=335,000 \mathrm{u} / \mathrm{L}$; prothrombin activity $=10 \%$; international normalized ratio $=5.84$; activated thromboplastin time $=84$ seconds; sodium $=135 \mathrm{mmol} . \mathrm{L}^{-1}$; potassium $=3.4 \mathrm{mmol} \cdot \mathrm{L}^{-1} ; \mathrm{BUN}=120 \mathrm{mg} \cdot \mathrm{dL}^{-1} ;$ creatinine $=$ $2.17 \mathrm{mg} \cdot \mathrm{dL}^{-1}$.

Electrocardiogram: atrial fibrillation. Transthoracic echocardiogram: important increase of the right and left atriums; important dilation of the right ventricle; moderate dilation of the left ventricle with septal and inferior akinesia and hypokinesia of the other walls. Ejection fraction $22 \%$; important mitral and tricuspid valve regurgitation; systolic pulmonary pressure estimated at $55 \mathrm{mmHg}$.

It was decided to perform a regional block (femoral and sciatic) for the surgical procedure. Monitoring consisted of non-invasive blood pressure, pulse oximetry, and cardioscope. Intravenous midazolam $2 \mathrm{mg}$, and fentanyl $50 \mu \mathrm{g}$ were administered. The femoral and sciatic nerve blocks followed the technique described in case 1. The surgery was performed without intercurrences, and it lasted 1 hour and 30 minutes. In the postoperative period, the patient did not present hematoma in the site of puncture, and the exam did not show motor and sensorial changes in the territory of the femoral and sciatic nerves. The patient remained without complaints of pain in the first 12 hours after the blockade.

\section{DISCUSSION}

Anticoagulation imposes specific restrictions to the use of classic regional blocks. In the cases reported, neuroaxis block was contraindicated due to the risk of bleeding in sites of difficult compression and to formation of spinal hematoma ${ }^{12}$. On a review of the literature between 1906 and 1994, 61 cases of spinal hematoma, among which 42 patients had coagulation abnormalities, were described. As for the anesthetic technique, 15 patients received spinal and 46 epidural block; an epidural catheter was placed in 32 patients, only $38 \%$ of the patients showed partial or total recovery of the neurologic deficit, demonstrating the severity of a spinal hematoma ${ }^{13}$.

The presence of preexisting pulmonary disease is one of the main risk factors for postoperative pulmonary complications, increasing the time of hospitalization and morbidity and mortality ${ }^{14,15}$. In patients with pneumonia, whenever possible the procedure should be postponed for two weeks to avoid severe postoperative pulmonary complications ${ }^{16}$. General anesthesia was not an adequate option in the first case, considering the need of manipulation of the airways of a patient with pneumonia.

With those considerations, the benefits of an ultrasoundguided peripheral nerve block have been classified as superior to the risks associated with neuroaxis blocks in situations of anticoagulation and to general anesthesia with tracheal intubation in patients with pneumonia.

Few studies have compared the complication index between ultrasound- and neurostimulation-guided techniques. Until now, the difference in the risk of nerve lesion, pneumothorax, or intoxication by local anesthetics among the different techniques has not been compared. Among the complications seen in the femoral and sciatic blocks, the reduction of the risk of accidental vascular puncture is the only complication in which the ultrasound-guided technique shows advantage ${ }^{1}$.

Classic regional techniques oriented by paresthesia or neurostimulation have higher risk of vascular lesions, especially in patients with possible anatomic vascular changes due to prior surgeries at the puncture site ${ }^{1-7}$. Nowadays, with the development of ultrasound equipment and methods, the precise identification of vascular and nerve structures is possible. This allows the ultrasound-guided puncture to be more precise, both to achieve the area of interest and to minimize the risk of accidental vascular lesion. Note that similar to any technique the success and complications rates are related to the experience of the professional.

Although the association of both techniques, ultrasound and neurostimulation, increases the cost of the procedure, it increases its safety and reduces even more the risk of failure. In the present case, in which the blockades were performed by residents in a teaching hospital, the association of both techniques was also didactic making it easier the learning and training.

In the cases reported here, the use of the ultrasound was fundamental for greater safety when performing the regional block, since it was associated with a higher risk of accidental vascular lesion by the classic technique, in both cases, due to the anatomic changes of the femoral region related to prior surgeries (femoro-popliteal graft).

Until now, peripheral nerve blocks are not recommended in anticoagulated patients or in those with coagulopathies ${ }^{12}$. However, considering that few reports on ultrasound-guided regional blocks in the presence of coagulopathies exist, the safety of this technique under those conditions has not been established.

Therefore, until well-fundamented evidence are obtained we should be based in experience and in the evaluation of each case weighing the risk of the development of hematomas and the benefits of peripheral nerve blocks for each specific situation. 


\section{REFERÊNCIAS / REFERENCES}

01. Kapral S, Greher M, Huber G et al. - Ultrasonographic guidance improves the success rate of interscalene brachial plexus blockade. Reg Anesth Pain Med, 2008;33:253-258.

02. Perlas A, Brull R, Chan VWS et al. - Ultrasound guidance improves the success of sciatic nerve block at the popliteal fossa. Reg Anesth Pain Med, 2008;33:259-265.

03. Sauter AR, Dodgson MS, Stubhaug A et al. - Electrical nerve stimulation or ultrasound guidance for lateral sagittal infraclavicular blocks: a randomized, controlled, observer-blinded, comparative study. Anesth Analg, 2008;106:1910-1915.

04. Chan VW, Perlas A, McCartney CJ et al. - Ultrasound guidance improves success rate of axillary brachial plexus block. Can J Anaesth, 2007;54:176-182.

05. Domingo-Triado V, Selfa S, Martınez F et al. - Ultrasound guidance for lateral midfemoral sciatic nerve block: a prospective, comparative, randomized study. Anesth Analg, 2007;104:1270-1274.

06. Williams SR, Chouinard P, Arcand G et al. - Ultrasound guidance speeds execution and improves the quality of supraclavicular block. Anesth Analg, 2003;97:1518-1523.

07. Abrahams MS, Aziz MF, Fu RF et al. - Ultrasound guidance compared with electrical neurostimulation for peripheral nerve block: a systematic review and meta-analysis of randomized controlled trials. $\mathrm{Br} \mathrm{J}$ Anaesth, 2009;102:408-417.

08. Warman P, Nicholls B - Ultrasound-guided nerve blocks: efficacy and safety. Best Pract Res Clin Anaesthesiol, 2009;23:313-326.

09. Koscielniak-Nielsen ZJ - Ultrasound-guided peripheral nerve blocks: what are the benefits? Acta Anaesthesiol Scand, 2008;52:727-737.

10. Bigeleisen PE - Ultrasound-guided infraclavicular block in an anticoagulated and anesthetized patient. Anesth Analg, 2007;104:1285-1287.

11. Khelemsky Y, Rosenblatt MA - Ultrasound-guided supraclavicular block in a patient anticoagulated with argatroban. Pain Pract. 2008:8:152.

12. Horlocker TT, Wedel DJ, Benzon $\mathrm{H}$ et al. - Regional anesthesia in the anticoagulated patient: defining the risks (the second ASRA Consensus Conference on Neuraxial Anesthesia and Anticoagulation). Reg Anesth Pain Med, 2003;28:172-197.
13. Vandermeulen EP, Van Aken $\mathrm{H}$, Vermylen $\mathrm{J}$ - Anticoagulants and spinal-epidural anesthesia. Anesth Analg 1994;79:1165-1177.

14. Behr $\mathrm{J}$-Optimizing preoperative lung function. Curr Opin Anaesthesiol, 2001;14:65-69.

15. Smetana GW - Preoperative pulmonary evaluation. N Engl J Med, 1999;340:937-944

16. Nishiyama T, Hanaoka K - Does common cold increase perioperative respiratory complications in adults? Masui, 2005;54:643-647.

Resumen: Ferraro LHC, Tardelli MA, Yamashita AM, Cardone JDB, Kishi JM - Bloqueo de los Nervios Femoral e Isquiático Guiados por Ultrasonido en Paciente Anticoagulado. Relato de Casos.

Justificativa y objetivos: El uso del ultrasonido para guiar la punción en bloqueos de nervios periféricos se ha convertido cada vez más en una práctica frecuente. Con la menor probabilidad de promover lesiones vasculares, el ultrasonido se convierte en un instrumento interesante en la realización de bloqueos periféricos, especialmente en los pacientes que usan anticoagulantes o con disturbios de la coagulación. El objetivo de este estudio fue relatar dos casos en que se realizaron los bloqueos isquiático y femoral guiados por ultrasonido en pacientes anticoagulados.

Relato de los casos: En el primer caso, la cirugía realizada consistió en la amputación del pie anterior izquierdo en función de una necrosis y de señales de infección. El segundo caso, fue una limpieza quirúrgica de la rodilla izquierda. Los pacientes presentaron disturbios de coagulación con una actividad de protrombina y tiempo de tromboplastina activado por encima de los valores normales. Los dos pacientes se sometieron al bloqueo femoral e isquiático guiado por ultrasonido, evolucionando sin alteración motora o sensitiva en los territorios de esos nervios y sin hematoma en la región local de la punción.

Conclusiones: La anticoagulación impone ciertas restricciones a la aplicación de las técnicas anestésicas regionales clásicas. Con el avance de los equipos y métodos de ultrasonido, hoy por hoy se puede identificar con alta precisión las estructuras vasculares y neurales. Eso posibilita que la punción guiada por ultrasonido sea más exacta, tanto para alcanzar el área de interés como para minimizar los riesgos de lesión vascular accidental. Hasta el presente momento, no se recomienda la realización de bloqueo periférico en pacientes anticoagulados o portadores de coagulopatías. Sin embargo, considerando que existen pocos relatos sobre bloqueos regionales con ultrasonido en situaciones de coagulopatías, la seguridad de tal técnica en esas condiciones todavía no se ha establecido. 